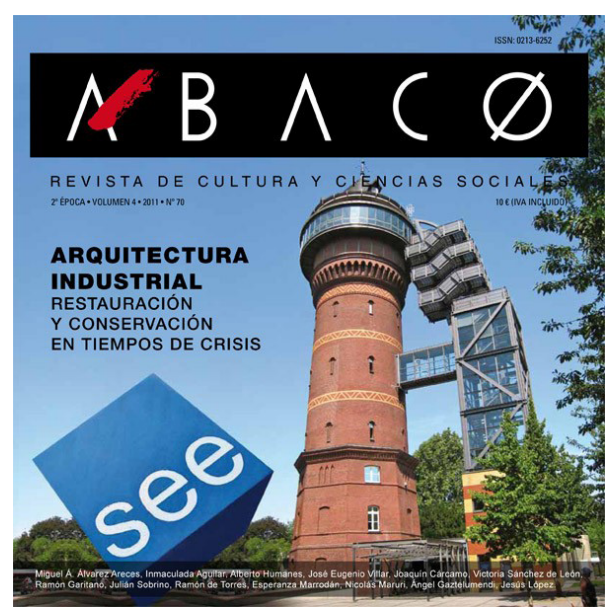

\title{
ÁBACO. REVISTA DE CULTURA Y CIENCIAS SOCIALES, № 70 DEDICADA A “ARQUITECTURA INDUSTRIAL. RESTAURACIÓN Y CONSERVACIÓN EN TIEMPOS DE CRISIS"
}

\author{
EDITORIAl cICEES, GIJóN - ESPAÑA, 2014
}

RESEÑA DE JOAN FELIU FrRANCH

Quisiera, desde la revista De-venir, recomendar otra revista científica, mucho más multidisciplinar, trasversal, y quizá por ello no tan especializada, aunque no exenta de calidad. Se trata de Ábaco, sin duda una de las revistas de cultura y ciencias sociales más importante del sector dentro del panorama internacional en lengua española. Ciertamente, su periodicidad trimestral hace que quizá el tema monográfico que la ocupe en el momento en que usted lee estas líneas no sea de su interés, pero le recomiendo rebusque en su web entre sus más de 800 trabajos publicados y escritos por importantes autores pertenecientes al ámbito cultural y social internacional, seguro que sorprenderá.

La revista trata, habitualmente, una monografía sobre cuestiones de actualidad desde un punto de vista plural e interdisciplinar. De este modo, los trabajos se orientan a la sociología, política, filosofía, fenómeno cultural, economía, psicología social, sin perder el eje temático monográfico que centre el número en cuestión. Es, por tanto, un vehículo de reflexión, investigación y debate intemporal e interdisciplinario que incorpora en sus páginas un horizonte amplio, universal, como los mismos hechos e ideas sobre los que trata de reflexionar y debatir. La razón de recensionar esta revista se encuentra en el excelente Ábaco $\mathrm{n}^{\circ} 75$, titulado Espacios públicos. Conflicto y convivencia. En este número, último del año 2013, cuenta con excelentes reflexiones, entre las que me gustaría destacar tres artículos (no todos, pues me extendería mucho).

Assumpta Aneas y Abdelsalam Basha firman el texto El espacio público como agente de movilización política y ciudadana: El caso de la Plaza Tahrir, un ejemplo de ocupación del espacio no sólo física, sino simbólica y espiritual que volvió a dar confianza e identidad ciudadana a una abrumadora mayoría de la sociedad egipcia de todas edades y posiciones sociales.

Mirella Loda es la autora de Espacios Públicos, una aproximación desde la geografía urbana: Los mercados históricos, analizados desde la perspectiva de la geografía social y urbana, es decir, entendiendo los mercados no solo como lugares de compra y venta, sino como espacios de relación en los que los actos de compra y venta son parte de un sistema más amplio de las relaciones sociales tan importantes como el propio intercambio económico que las genera. El artículo ilustra estas tendencias tomando como base el mercado histórico florentino de San Lorenzo.

Y quisiera recomendar especialmente a Miguel Silva Graça, que aborda en $E l$ nuevo espacio (público): conflicto y la convivencia entre las esferas pública y privada en Portugal y Europa la hipótesis de que si la ciudad ya no es lo que era, tampoco lo es ya su espacio público. Acompañando el advenimiento de una «nueva condición urbana», analiza cómo surgen - más allá de la tradicional red de espacios públicos- un conjunto de otros lugares, que suponen variaciones de los paisajes metropolitanos en los que se despliegan. Este fenómeno, común a la mayoría de las zonas urbanas europeas, y también en el Perú, se materializa en un hipertexto de equipamientos lúdico-comerciales - como estadios, parques temáticos, ferias industriales o pabellones para muestras-que constituye el campo acción de los usos de una cultura post-urbana, condensada en el tiempo y dispersa en el espacio. Un muy interesante texto muy actual en el ámbito peruano, pues centra la nueva representatividad urbana en el centro comercial. Y no solo por ser uno de los elementos más llamativos de la ciudad contemporánea, sino también por materializar el nuevo espacio público para ser a la vez lugar de consumo y de nuevas centralidades en las áreas metropolitanas actuales, hecho que no podemos seguir ignorando en una reflexión sobre el presente y el futuro de la propia ciudad. 


\section{GESTIÓN DEL PATRIMONIO CULTURAL Y CENTROS HISTÓRICOS LATINOAMERICANOS}

\author{
JOSÉ HAYAKAWA CASAS \\ EDITORIAL DE LA UNIVERSIDAD NACIONAL DE INGENIERÍA, 2010.
}

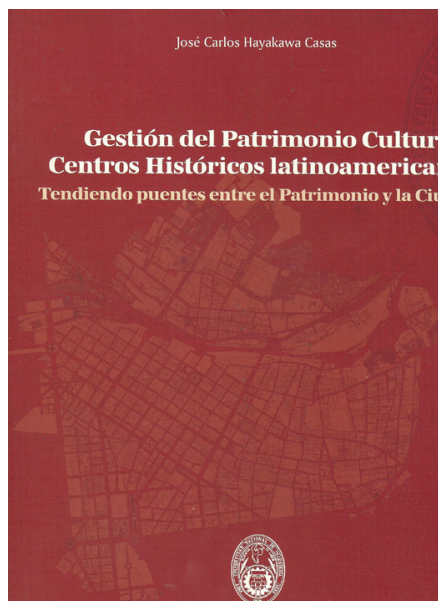

RESEÑA DE INÉS DEL ÁGUILA RÍOS

Después de disfrutar y aprender del libro que nos entrega José Hayakawa, viene a mi memoria la labor patrimonialista desarrollada como Director de Patrimonio de la Municipalidad Metropolitana de Lima donde fue un promotor de la relación con los museos del Centro Histórico de Lima. Cada página presenta respuestas a numerosos temas sobre la gestión del patrimonio cultural, destacando varios que luego desarrollo.

Estoy totalmente de acuerdo con el Dr. Joan Feliu cuando destaca en este libro y declara que "El arquitecto Hayakawa ha entendido muy bien lo que decía la Unesco, que lo más importante no era construir escuelas en países desvastados ó publicar hallazgos científicos. El objetivo es mucho más amplio y ambicioso: construir la paz en la mente de los hombres mediante la educación, la cultura, las ciencias y la comunicación. En este sentido, la gestión de los Centros Históricos de Latinoamérica que aquí se aborda parte del desarrollo de las capacidades humanas e institucionales en sus diferentes ámbitos de actuación". Las reflexiones del autor construyen un corpus disciplinar e ideológico que en sus palabras "aspira a ser, desde la perspectiva de nuestras propias circunstancias, una puesta en cuestión de algunos de sus argumentos, como el retorno a la ciudad construida o la apropiación social del Patrimonio“.

La estructura del libro revela datos que son producto de su intenso trabajo de campo y gabinete y que comprende tres capítulos: Un marco teórico. Un análisis de casos. Lecciones aprendidas.

Los contenidos de cada capítulo tienen un orden lógico-metodológico por su afán didáctico, acercando al estado de la cuestión sobre la gestión del patrimonio, actualizando y discutiendo los diferentes enfoques. Esta pedagogía ordena las ideas, define y analiza los conceptos involucrados en la gestión del Patrimonio. El abordaje ha considerado los aportes de la historia, de la sociología, de la filosofía y de la antropología, lo que ha dado lugar a un corpus informativo de reciente debate en torno a los temas globales sobre el patrimonio cultural. El autor pone de relieve la idea de que el Patrimonio al ser un concepto relativo, temporal, histórico puede resultar de la imposición estimativa de un grupo aunque lo esperado es que se origine en el diálogo y en los consensos entre los actores sociales, lo que determina que la significación del patrimonio resulte de la sumatoria de valores de los distintos grupos socioculturales.

wAl introducir el tema sobre enfoques del Patrimonio en el ámbito Europeo y establecer analogías entre las miradas de los anglosajones y franceses, el autor señala enfáticamente que Francia es históricamente una verdadera precursora del movimiento patrimonializador al haber tomado conciencia primigeniamente de sus bienes legados en nombre del interés común, hecho que se remonta a la Revolución Francesa mientras que la cultura anglosajona tiene una dinámica patrimonializadora desde los actores privados que aportan al discurso patrimonial. En este proceso conceptual, la cultura está presente como hilo conductor de los debates sobre interculturalidad, multiculturalidad y transculturalidad. Todo ello en el marco de los conceptos de unidad y diversidad. 


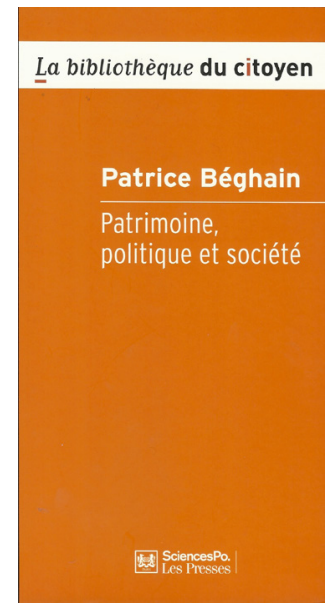

Nacida en medio de una aproximación prioritariamente estética, la noción de patrimonio conoce desde hace algunos decenios un desarrollo internacional considerable y se ve, en un medio marcado por la diversificación cultural de las sociedades y por la mundialización, expuesta a nuevos desafíos.

La explosión del turismo de masas, la cual tiene por corolarios la uniformización y el mercantilismo así como el debilitamiento del rol del Estado y la primacía de lo económico hacen pensar en los nuevos riesgos que hay sobre la integridad de los bienes patrimoniales, sean estos materiales o inmateriales. Ellos también deben ser conservados de la amenaza conjunta del comunitarismo y del repliegue identitario, a fin de devenir en valor de intercambio y compartimiento. La autora apela a un nuevo "pacto patrimonial" tanto al interior de cada sociedad como en las relaciones entre países, con un balance entre la delicada cuestión del retorno de los bienes culturales a su país de origen, que se desarrolla aquí como objeto de un aproximación comprometida.

Este libro posee una sección introductoria que plantea una reflexión diacrónica y amplia acerca de la evolución de la noción del patrimonio,

\title{
PATRIMOINE, POLITIQUE ET SOCIETÉ
}

\author{
PATRICE BEGHÁIN \\ PRESSES DE SCIENCES PO, PARÍS - FRANCIA, 2012
}

RESEÑA DE JOSÉ HAYAKAWA CASAS

ya desde los orígenes de la humanidad como noción de preservación contra el normal desgate del tiempo sobre todo, pasa por la vocación de los coleccionistas más ilustrados para finalmente, llegar al surgimiento de la noción de actuación pública asociado al Estado-Nación de la era moderna como herencia compartida. Dicha reflexión llega a las vicisitudes actuales.

El primer capítulo de esta publicación nos presenta de una forma sintética, pero profunda, la relación entre patrimonio y política, afirmando su condición de binomio, para lo cual propone un recorrido que va desde los humanistas italianos a los pontífices romanos; la aparición de la experiencia francesa desde los orígenes mismos de la Revolución Francesa hasta la llegada del anticlericalismo para finiquitar esta parte con los expoliadores y depredadores del patrimonio. El segundo capítulo aborda el tránsito de la noción de patrimonio (en singular) a patrimonios (en plural), para lo cual desarrolla el avance protagónico de los museos, el "síndrome del Gran Louvre”, la mutación que afrontan los museos en relación a nuevos desafíos, las tradicionales prácticas restrictivas del patrimonio monumental, el pretendido liderazgo de "cierto patrimonio" y la aparición reciente del "patrimonio cultural inmaterial" como gran avance e innovación en este devenir disciplinar y ontológico. La tercera parte incide en el buen y mal uso de la economía del patrimonio que eventualmente propicia y otras veces desvirtúa el sentido de dicho patrimonio. La cuarta parte reflexiona sobre la relación entre "artificio" y "realidad", a través de la ruptura del vínculo social y su instrumentalización. El quinto capítulo propone la evolución desde el monumento al territorio, desde los tránsitos "del contexto a la pertenencia" o "la ciudad como patrimonio". La sexta y sétima parte desarrollan la identidad como relación convergencia-divergencia a partir del "retorno a lo local" y la dicotomía "universal y nacional". Finalmente, la octava parte reconstruye el trinomio memoria, poder y patrimonio en términos de las diversas combinaciones y manifestaciones que sus desiguales relaciones poseen. 


\section{MAS: MEDIO / ARQUITECTURA / SOCIEDAD. REVISTA INSTITUCIONAL IRADAS AL PATRIMONIO}

\author{
REVISTA INSTITUCIONAL DEL COLEGIO DE ARQUITECTOS DEL PERÚ, REGIONAL DE \\ AREQUIPA N¹ DEDICADA A "PATRIMONIO" \\ COLEGIO DE ARQUITECTOS DEL PERÚ, REGIONAL DE AREQUIPA, AREQUIPA, PERÚ, 2011.
}

RESEÑA POR JOSÉ HAYAKAWA CASAS

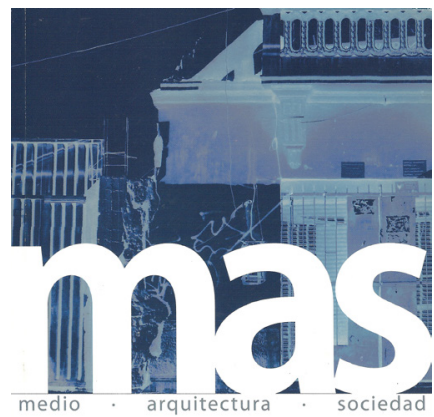

patrimonio
Nos aproximamos a una breve, pero consistente revista que más allá de su carácter sintético posee aspiraciones refundacionales en el ámbito del conocimiento de lo patrimonial, en el marco mayor del mundo académico-profesional del sur peruano. De hecho, el mismo decano regional del Colegio de Arquitectos del Perú- Región Arequipa arquitecto Luis Alemán Abad mencionaba entre los principales méritos de esta publicación: "Expertos y destacados profesionales en el tema de patrimonio nos hacen conocer sus planteamientos, propuestas y opiniones, que, sin lugar a dudas, habrán de enriquecer el bagaje de experiencias y conocimientos que tenemos al respecto, contribuyendo con ello, a fortalecer nuestra capacitación en un tema que es fundamental para el ejercicio eficiente de nuestra labor profesional [...]".

La revista presenta varios tema interesantes, pero en esta breve reseña solo enfatizaremos algunos que consideramos representativos de su calidad, rigor y amplitud de enfoque, reflexiones y capacidad propositiva.

Destacan los testimonios que tienen como finalidad la recupera- ción de la memoria académico y profesional gestada desde la misma circunstancia del sur andino peruano y específicamente arequipeño tales como la entrevista con el destacado arquitecto Álvaro Pastor quien enfatiza en el concepto que "La ciudad es un organismo vino, transmite su malestar y muestra su lado bueno, hay que escucharla y tratarla como tal [...]". En la misma línea, está el testimonio del arquitecto Luis Maldonado Véliz quien lúcidamente reconceptúa que el "patrimonio significa pertenencia, propiedad. La población que habita o usa un bien debe sentirse propietaria de ese bien, y si tiene valor, debe participar en el proceso de su recuperación".

Asimismo, existen aportaciones muy significativas tales como la del arquitecto Ramón Gutiérrez quien insiste en temas de apropiación social de los bienes al mencionar que el patrimonio es aquello que constituyen los elementos de vínculo, de referencia, de afectividades, de posibilidades de (auto)reconocimiento por parte del colectivo como com(unidad). Asimismo, el arquitecto Ángel Guillén desarrolla un breve corpus teórico acerca de los paisajes culturales incidiendo en la construcción de un nuevo paradigma disciplinar el cual a su vez exige una lectura endógena del ambiente, un reconocimiento de su respectivo valor patrimonial y una reinterpretación innovadora y repotenciada de los territorios. De otra forma la licenciada Ángela Delgado aborda también la temática del patrimonio, pero en su relación con la ciudad, "repensándola” y acentuando los procesos dialógicos y dicotómicos que en ella se (re)producen y se vinculan con las experiencia de planificación como refiere, ya que la planificación urbana interviene en todos los procesos de comunicación entre los habitantes de una ciudad. Finalmente, es destacable artículo del arquitecto William Palomino quien a partir del estudio histórico de la Casona de la Hostería en Arequipa recupera y pone en valor la toponimia, la estructura básica de la ciudad, sus lógicas territoriales y su conectividad ancestral que pervive y nos interpela en la ciudad hoy. 